\title{
Subsurface Microstructural Evolution of High-Pressure Diecast A365: From Cast to Cold-Sprayed and Heat-Treated Conditions
}

\author{
Alino Te ${ }^{1,2,+}$, , Bryer C. Sousa ${ }^{1, *(\mathbb{C}}$, Brajendra Mishra ${ }^{1, *(\mathbb{C})}$ and Danielle L. Cote ${ }^{1, * \mathbb{C}}$ \\ 1 Materials \& Manufacturing Engineering, Worcester Polytechnic Institute, Worcester, MA 01609, USA \\ 2 Solvus Global, 104 Prescott Street, Worcester, MA 01605, USA; alino.te@solvusglobal.com \\ * Correspondence: bcsousa@wpi.edu (B.C.S.); bmishra@wpi.edu (B.M.); dlcote2@wpi.edu (D.L.C.) \\ + Current affiliation: Solvus Global, 104 Prescott Street, Worcester, MA 01605, USA.
}

Citation: Te, A.; Sousa, B.C.; Mishra, B.; Cote, D.L. Subsurface Microstructural Evolution of High-Pressure Diecast A365: From Cast to Cold-Sprayed and Heat-Treated Conditions. Metals 2021, 11, 432. https://doi.org/10.3390/ met11030432

Received: 30 December 2020

Accepted: 23 February 2021

Published: 5 March 2021

Publisher's Note: MDPI stays neutral with regard to jurisdictional claims in published maps and institutional affiliations.

Copyright: (c) 2021 by the authors. Licensee MDPI, Basel, Switzerland. This article is an open access article distributed under the terms and conditions of the Creative Commons Attribution (CC BY) license (https:// creativecommons.org/licenses/by/ $4.0 /)$.
Abstract: The use of cold spray deposition, coupled with diffusion-driven thermal postprocessing, is considered herein as a surface modification process such that near-surface microstructural, micromechanical, and microchemical property improvements can be procured for cost-effective and common aluminum alloy castings. Since the present work was an exploratory investigation into the realm of cold spray induced, high-pressure diecast aluminum subsurface property development and evolution, as well as surface modification, one significant aim was to formalize a set of fundamental observations for continued consideration of such an approach to achieving premium aluminum alloy properties from cost-effective alternatives. Nickel, copper, and titanium cold spray modified nearsurface regions of the cost-effective high-pressure diecast A365 system was considered. Near-surface, subsurface, and surface evolution was documented across each of the three pure metal coatings. The analysis was continued across two postprocessing coating-substrate atomic diffusion inspired heat-treated conditions as well. Using energy-dispersive X-ray spectroscopy, field-emission scanning electron microscopy, optical microscopy, and various insights gleaned from an original contextualization of the relevant cold spray literature, noteworthy results were recorded and discussed herein. When copper feedstock was employed alongside thermal postprocessing, diverse surface-based intermetallic compounds formed alongside exotic diffusion zones and severely oxidized regions, thus eliminating thermally activated copper cold-sprayed consolidations from future work too. However, both nickel and titanium cold spray surface modification processing demonstrated potential and promise if correct processing stages were performed directly and chronologically. Consequently, a platform is presented for further research on cold sprayed surface microstructural and property modification of cost-effective alloyed aluminum castings.

Keywords: high-pressure die-casting; alloyed aluminum; cold spray processing; alloy surface modification; intermetallic compounds; bimetallic systems and processing; copper; nickel; titanium; atomic diffusion; heat treating

\section{Introduction}

Cold gas dynamic spray (CGDS), or less formally, cold spray, is a solid-state materials consolidation and processing technology that utilizes particulate feedstock that is transported via a heated carrier gas stream until exiting a de Laval nozzle and then supersonically impacting a substrate [1]. CGDS processing was initially conceptualized as a tool for achieving coatings with unique and application-specific properties [2]. Following the accidental discovery of CGDS processing in the Soviet Union during the 1980s, the solidstate technological process was adopted by the remanufacturing and repair [3] sector as well as the additive manufacturing (AM) community [4]. Supersonically accelerated particles are deposited onto a substrate with high strain rates to consolidate material(s) in a layer-by-layer fashion until a thickness or geometry is achieved [5]. Therefore, successful CGDS processing and materials consolidation depend upon particle-substrate and 
particle-particle metallurgical and mechanical bonding. CGDS processing parameters vary from the nozzle type to the selection of powder composition and gas source. Typically, inert gases are used, such as helium or nitrogen [6], but compressed air has been employed as well [7]. Feedstock powder for CGDS processing typically has a diameter range from approximately 5 to $100 \mu \mathrm{m}$. These particles generally achieve velocities between 300 and $1200 \mathrm{~m} / \mathrm{s}$.

Recent decades have seen a transitioning of CGDS from governmental or national labs and academia to the commercial and industrial sector due to its extreme flexibility in upscale robotics and material permutations [8-10]. In any case, advanced CGDS processing development continues to emerge and evolve through unique applications by way of invoking a process-structure-property-performance perspective [11] or a throughprocess framework [12]. Consequently, the resultant materials consolidated via CGDS have reportedly achieved appreciable technological readiness levels, scientific robustness, and economic viability [13]. In turn, one of the aims of the present work was to contribute to the continued compilation of contemporary findings surrounding CGDS processing with reverence to prior academic work via the lens of a novel exploratory study on substrate near-surface and subsurface microstructural evolution following CGDS deposition and thermal postprocessing.

With the aforementioned in mind, the present work detailed herein took a precursory and exploratory approach to the inspection of CGDS-based material surface modification processing as a potentially suitable pathway to the procurement of improved near-surface properties regarding fracture or impact toughness and strength relative to the original surface state of the substrate material. This work was motivated by the aluminum automotive industry, which seeks to produce cost-effective cast components that achieve improved mechanical properties, i.e., properties typically associated with premium aluminum alloys such as A201.

Premium aluminum alloys such as A201 are generally sought after due to their excellent toughness and high-temperature properties. The cost of A201, the difficulties, and the human hazards associated with processing such an alloy have motivated engineers within the automotive sector to select cost-effective alternatives. Material classes such as steel systems are utilized in many applications where toughness is critical, even though steel increases the overall vehicular mass and lowers fuel efficiency. To avoid the use of steel (as well as the complications that arise from processing A201 alloyed components), previous research has developed a new aluminum alloy known as NASA-427 for automotive applications where high impact toughness is a critical property. Though the approach of novel alloy design warrants attention and continued consideration within the automotive industry, the improved fuel efficiency achieved when using NASA-427 instead of steel, the processing capacity of NASA-427, and the mechanical properties of NASA-427 do not address the problem of being prohibitively costly when compared with typical, cost-effective aluminum alloys. Thus, if one were to approach the issue of employing a lightweight aluminum material for impact-critical automotive applications with the minimal economic expense and increased processing compliance, then sophisticated chemical or mechanical surface modification of common alloys, such as A356, A365, and E357, would serve as an advanced manufacturing solution. Noted throughout the present manuscript, A365 was selected as the high-pressure diecast (HPDC) aluminum alloy of relevance herein due to its pervasiveness in aluminum foundries.

That said, this work also takes a precursory scientific look into current surface modification processing techniques. In doing so, the fundamentally applied scientific exploration presented herein aims to provide automotive materials and materials processing engineers with structure-processing-properties insights. In turn, such insights can subsequently be linked to common castable aluminum alloys and their application-specific performances as a function of the surface modification method utilized. Accordingly, this exploratory investigation characterizes the microstructural, micromechanical, and microchemical behaviors as a function of the CGDS surface modification techniques considered herein. Moreover, 
the characterization and discussion reported herein provide a direction for future research and development surrounding the application of CGDS surface modification techniques for application-specific performance requirements in the automotive sector.

Accordingly, the CGDS surface modification process must show significant promise for achieving an improvement in such properties and be cost-effective and easily adaptable in a typical foundry or manufacturing downstream. Diffusion of foreign material from the CGDS coating(s) and into the substrate was investigated with various coating metals. The diffusion process was facilitated in the solution treatment step for the given substrate aluminum to strengthen the parts' subsurface region while maintaining standard heat treatments employed in the industry. This research aimed to provide a platform for further research into the practical effects of CGDS coating and thermal postprocessing on the coating-substrate's regional microstructural and microchemical properties.

Historically, CGDS thermal postprocessing work has been done on a self-similar substrate and feedstock combination(s), simplifying thermal processing optimization. For example, Rokni et al. not only recognized the fact that the powders utilized in [14] were sourced from precipitation-hardenable aluminum alloy compositions (Al 7075 in particular) and identified that the substrate used was wrought $\mathrm{Al} \mathrm{7075,} \mathrm{thus} \mathrm{capturing}$ feedstock-substrate self-similarity.

Thermal postprocessing remains invaluable as a means of enhancing deposited material performance. Much more research and development must be explored for different feedstock-substrate material combinations to properly understand the unique consequences stemming from multi-material systems adhered to one another via CGDS. At the same time, Rokni et al. also reconsidered and recorded thermal postprocessing induced relations for $\mathrm{Al} 7075$ feedstock particulates sprayed onto an Al 7075-T6 substrate in [15]. However, upon closer inspection of the published research of Rokni et al., their work mainly focused upon heat treating bulk CGDS materials detached from a sacrificial substrate, thus limiting the ability to compare to the analysis of Rokni et al. Such limited comparability stems from the fact that the current manuscript is concerned with subsurface and interfacial substratecoating property and structure evolution, rather than bulk CGDS material consolidation properties, as had been of considerable interest to Rokni et al.

Work has been conducted to improve the deposited material and primarily has been done with indifference to a sacrificial substrate. Prior work has also shown that CGDS can improve impact resistance and fracture toughness, among other mechanical properties, in the bulk material substrate systems from CGDS processing for a select set of powdersubstrate material combinations. Jafarlou et al. demonstrated improved mechanical properties of an AM 15-5 precipitation-hardenable stainless steel via thermal processing coupled with a CGDS-based consolidation of a thin chrome-carbide and nickel coating [16]. Furthermore, Yang et al. revealed that the CGDS consolidation of Al 5052 and other Albased coatings enhanced the "fatigue crack propagation performance" of a steel-based substrate [17].

Enhancements in fatigue or impact behavior improvements, wear resistance [18], tribological performance [19], hardness [20], and corrosion resistance [21] can all also follow from properly engineered and processed CGDS consolidations deposited onto target substrate specimens. Research by Huang et al. demonstrated a hypothesized balance between improved wear and corrosion resistance, room temperature ductility, and "good vibration damping properties," as articulated in [22].

Implementation of CGDS processing to deposit a strengthening or toughening agent upon a target substrate or base material has been shown to maintain a degree of potential and promise. A combination of efficient feedstock use, low-temperature application, and focused mechanical property manipulation will prove to be a powerful technique for the wider manufacturing industry as a more refined understanding emerges via highly nuanced and targeted subsequent studies. Further expanding CGDS technology and research has industrial implications ranging from the automotive sector to the aerospace industry. A hypothetical example could be of known weak points in auto frames. Suppose a localized 
section is prone to fatigue failure or requires more ductility for safety in crumple zones. In that case, CGDS could be employed to apply a toughening or strengthening component to targeted locations rather than an entire frame to improve mechanical properties. Work must be conducted to prove this approach's viability and thereafter the material combinations that would provide such mechanical improvements.

\section{Experimentation, Materials, and Methods}

The present research focuses on surface and subsurface microstructural development and evolution due to surface modification of structural alloys. To this end, a coating was deposited to the base material, and a heat treatment was applied to facilitate diffusion and, consequently, enhance subsurface properties and microstructures. The proposed materials to coat aluminum substrates are also known for alloying or strengthening enhancement mechanisms. The coating materials include copper, nickel, titanium, and zinc; however, only the first three pure metals could be utilized during the current work. The methods of electroplating, electroless plating, hot-dip galvanizing, and CGDS were considered and tested in an exploratory fashion. CGDS was determined to be the best in terms of continuity of the coating and lab-scale production reproducibility.

Copper was selected as it is the primary alloying constituent currently used in aerospace applications for these desired mechanical properties [23]. Nickel was chosen for the potential benefits found in nickel aluminide materials [24]. Nickel aluminide has excellent high-temperature properties, but processing at lower temperatures is complicated due to the material's brittleness [25]. Titanium was selected due to Ti's use in tool steels and Ti's known ability to refine aluminum's grain structure [26]. Furthermore, titanium nitride increases various mechanical properties, including impact strength, among other properties [27].

Subsize, cost-effective aluminum alloy substrates composed of A365 (see Table 1) and exposed to CGDS surface modification were produced via waterjet cutting from stock HPDC A365 aluminum donated by the aluminum division of Rio Tinto (Montreal, QC, Canada). Pre-waterjet-cut HPDC-A365 plates were approximately $229 \mathrm{~mm}$ by $76 \mathrm{~mm}$ by $3 \mathrm{~mm}$ in thickness. Plates were faced in a HAAS Mini Mill (Haas Automation, Inc., Oxnard, CA, USA) to a $2.5 \mathrm{~mm}$ uniform thickness (before waterjet cutting) in the Worcester Polytechnic Institute Machine Shops (Worcester, MA, USA). Parts were waterjet cut by Hydracadabra (Amesbury, MA, USA) at Arc Technologies, Inc., and now titled ARC Technologies, a Hexcel Company (Amesbury, MA, USA). The Applied Research Lab conducted CGDS processing of nickel, titanium, and copper feedstocks at Pennsylvania State University (State College, PA, USA). Cut samples before CGDS were wire brushed and cleaned with isopropyl alcohol. Accordingly, Figure 1 presents digital images of the waterjet-cut HPDC A365 substrate/base material in the as-cast condition (see Figure 1A) and as-CGDS-processed conditions too.

Table 1. Nominal composition of HPDC A365 base material provided by Rio Tinto.

\begin{tabular}{ccccccccc}
\hline \multicolumn{10}{c}{ Composition (wt. \%) } \\
\hline & $\mathrm{Al}$ & $\mathrm{Si}$ & $\mathrm{Fe}$ & $\mathrm{Cu}$ & $\mathrm{Mn}$ & $\mathrm{Mg}$ & $\mathrm{Zn}$ & $\mathrm{Ti}$ \\
\hline $\mathrm{A} 365$ & Bal. & 10.3 & 0.16 & $<0.01$ & 0.52 & 0.31 & $<0.01$ & 0.05 \\
\hline
\end{tabular}


$\mathbf{A}$

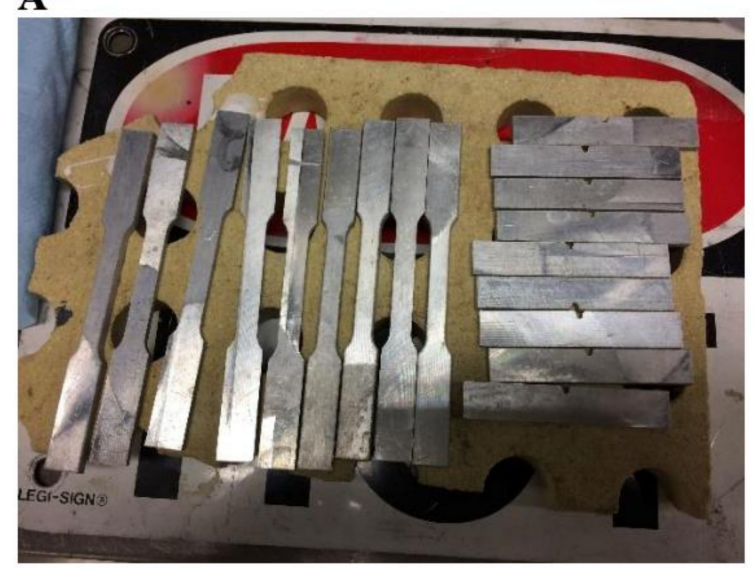

C

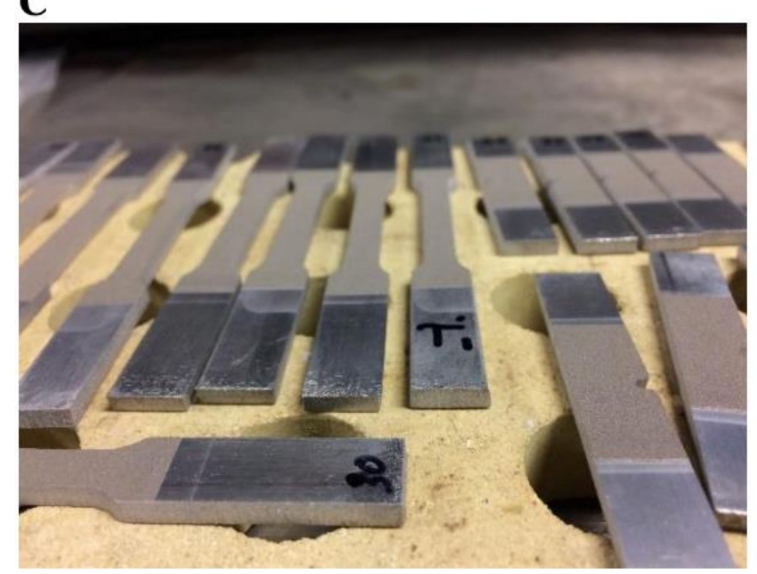

B

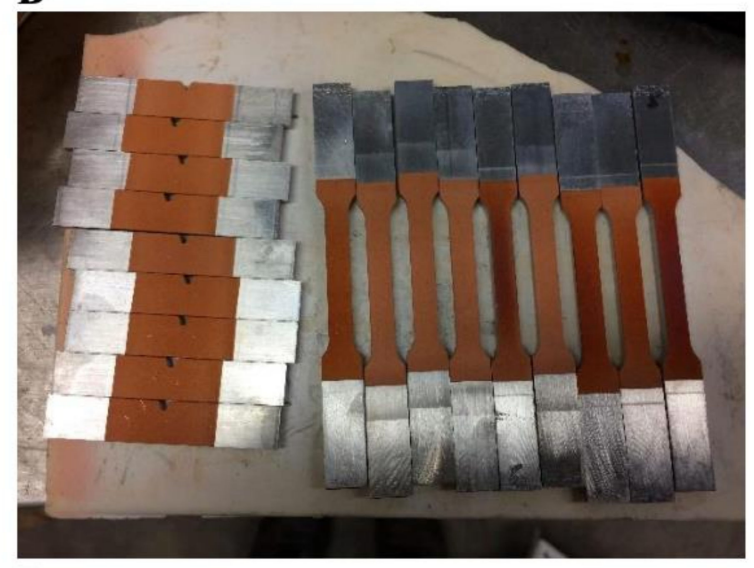

D

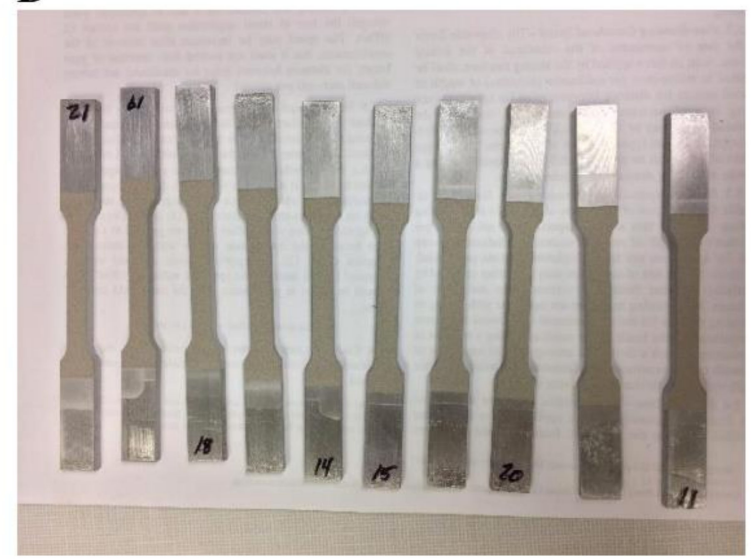

Figure 1. (A) Digital image of the waterjet cut HPDC A365 substrate/base material as reference specimens that therefore did not undergo cold gas dynamic spray (CGDS) processing. (B) Digital photo of the thinly coated and Cu CGDS processed A365 HPDC substrate specimens. (C,D) Digital images are similar to (B), where Ni and Ti were utilized as feedstock, respectively. For reference, the thickness of the base material (see (C) with the properly oriented specimen labeled " 30 ") was $2.5 \mathrm{~mm}$ before CGDS processing or postprocessing after that.

Solution treatments were conducted utilizing the parameters recommended by the aluminum division of Rio Tinto. A furnace was run at $500{ }^{\circ} \mathrm{C}$ for several hours to regulate and stabilize the system before applying the solution treatment. Samples were placed in the furnace and then allowed to sit until the associated thermocouples read $500{ }^{\circ} \mathrm{C}$ once again. Once the temperature was reached, a timer was set for $80 \mathrm{~min}$. After $80 \mathrm{~min}$ of hold time, the solution-treated specimens were removed and cooled by forced-air cooling. In turn, the following digital images were recorded, as shown in Figure 2. Most of the dramatic events surrounding diffusion-based chemical interactivity between the deposited CGDS coating and substrate material would have occurred during the solution treatment step due to the very high temperature relative to the melting point of the substrate's aluminum matrix. Note that T6 heat treatments, following solution treating, were also performed via the following conditions and parameters: natural, room temperature aging for $24 \mathrm{~h}$, followed by artificial aging in a furnace that was regulated once again at $170^{\circ} \mathrm{C}$ for several hours before introducing the sample, and finally holding the sample at $170{ }^{\circ} \mathrm{C}$ for $150 \mathrm{~min}$. 


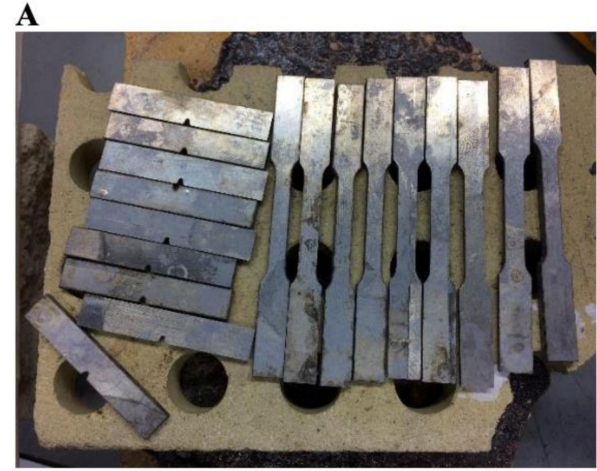

C

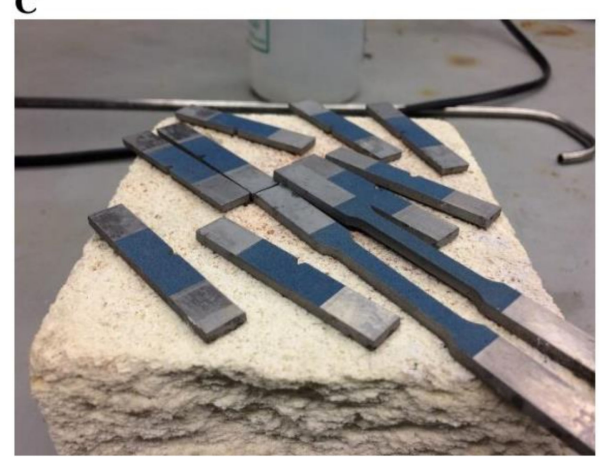

B

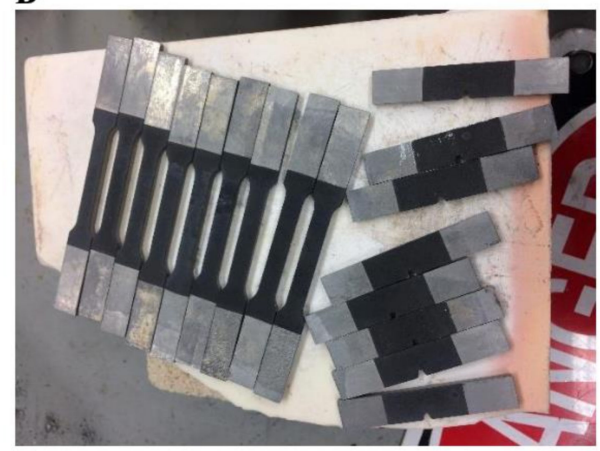

D

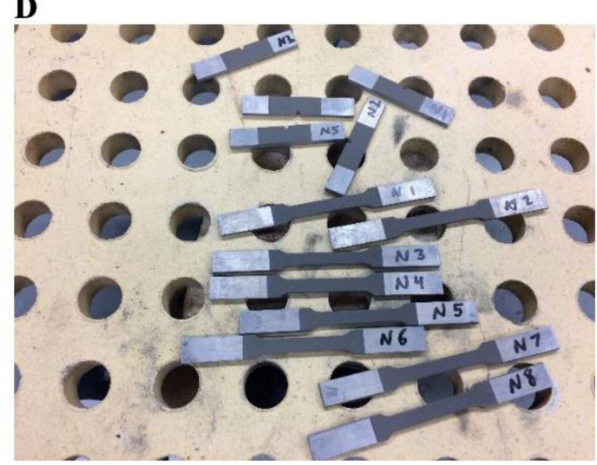

Figure 2. (A) Digital image of the thermally postprocessed HPDC A365 reference specimens procured during the current research effort. (B) Digital photo of the thermally postprocessed Cu CGDS coated HPDC A 365 substrate system. (C) Digital photo of the thermally postprocessed Ti CGDS coated HPDC A 365 substrate system. (D) Digital image of the thermally postprocessed Ni CGDS coated HPDC A 365 substrate system. Note that the same dimensional reference provided in Figure 1 holds here as well.

CGDS deposition of nickel, titanium, and copper feedstocks was conducted at the Applied Research Lab at Pennsylvania State University (State College, PA, USA) using proprietary and undisclosed processing procedures. The Applied Research Lab utilized nitrogen as the carrier gas for copper and nickel and helium for titanium. Furthermore, a VRC GEN III CGDS processing system (VRC Metal Systems, Box Elder, SD, USA) was utilized to deposit all three pure metal particulate feedstocks considered herein. The coatings' goal thickness was $100 \mu \mathrm{m}$ to provide sufficient diffusing material and achieve comparable coating thicknesses in light of the typical thickness ranges associated with alternative surface treatments such as electroless Ni plating. Unfortunately, only two broad face CGDS coating was deposited for each substrate sample, rather than all of the broad faces of the waterjet cut substrate specimens, thus preventing accurate macro-mechanical testing of the bimetallic systems considered.

CGDS-processed samples were compression mounted in a phenolic thermosetting resin via a Buehler Simplimet 4000 (Lake Bluff, IL, USA). According to standard metallographic practices, grinding and polishing was carried out using a Buehler Ecomet 300 grinder-polisher. Optical microscopy was performed using an inverted metallurgical microscope equipped with an Olympus Microscope Camera DP73 (Olympus Corporation, Shinjuku City, Tokyo, Japan). Energy-dispersive X-ray spectroscopy (EDS) was performed by way of an Oxford Instruments X-MaxN detector (Abingdon, Oxfordshire, UK) coupled with a JEOL JSM-7000F field emission SEM (Akishima, Tokyo, Japan).

Three powder suppliers were identified as being able to accommodate the smallbatch orders. The commercially pure Ti feedstock powder was obtained from Accushape, Inc. (Portland, OR, USA). Accordingly, the Ti feedstock was the only feedstock that was not produced via atomization-based approaches herein; thus, it yielded sponge-like or foam-like morphologies relative to the virtually spherical copper and nickel feedstock powders. Specifically, the gas-atomized nickel powder, which maintained a 270-mesh 
particle size distribution or condition, was produced by Praxair S.T. Technology, Inc. (Praxair, Inc., Danbury, CT, USA) with a product I.D. of NI-914-1. Unlike the atomized $\mathrm{Ni}$ powder, which was gas-atomized in an inert gas, the $\mathrm{Cu}$ powder was atomized using air (rather than an inert gas) and also underwent annealing by ACuPowder International, LLC (Union, NJ, USA), which now resides under the umbrella of Kymera International (Research Triangle Park, Durham, NC, USA).

\section{Results and Discussion}

Figure 3, in part, presents cross-sectional optical micrographs of the cast A365 substrate, as shown in Figure 3A, and the coated substrates. A secondary microstructural phase grain size gradient can be observed in Figure 3A. The A365 material yields a more refined grain size distribution towards the casting's surface and a coarser dendritic microstructure away from the casting's surface. The cross-sectionally oriented microstructure of the A365 was consistent with typical microstructures previously recorded for nominal A365 castings [28]. Specifically, the microstructure of the as-cast A365 system presented in Figure 3A was found to be consistent with the microstructure shown in [29], which noted "primary eutectic $\alpha$-Al dendrite grains with needle-like or acicular eutectic Si particles", which adequately captured the observations recorded herein.

$\mathbf{A}$

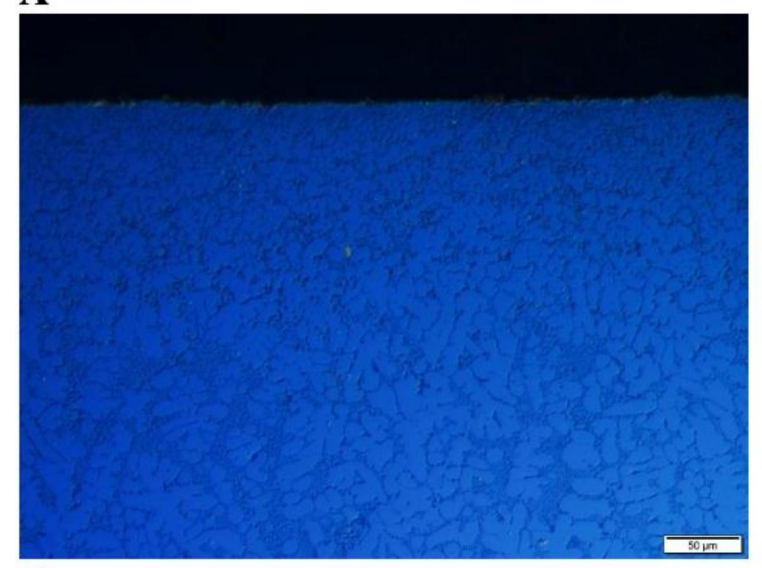

C

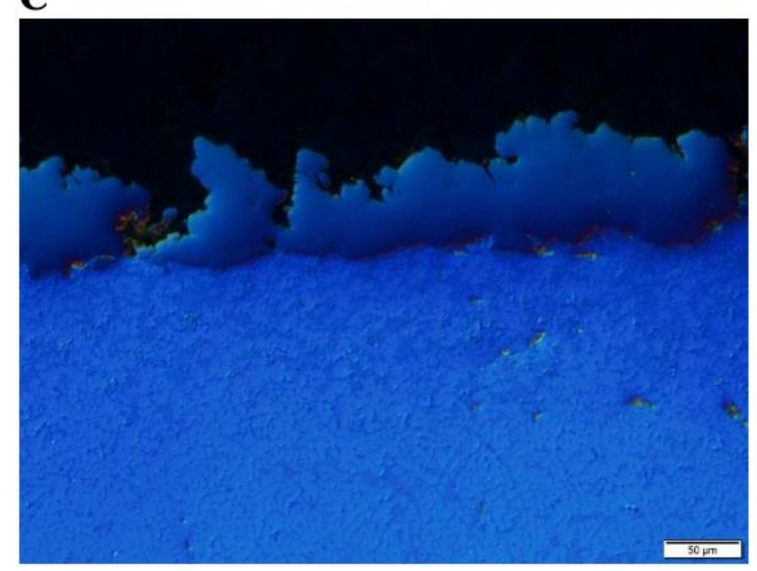

B

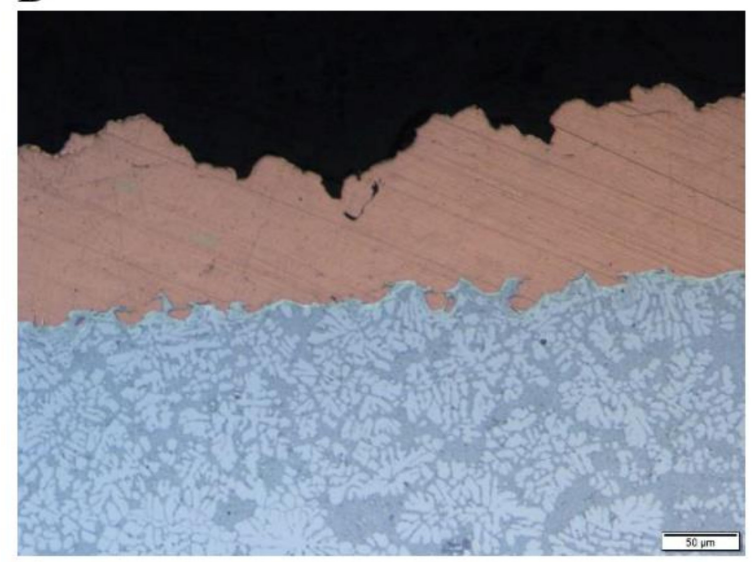

D

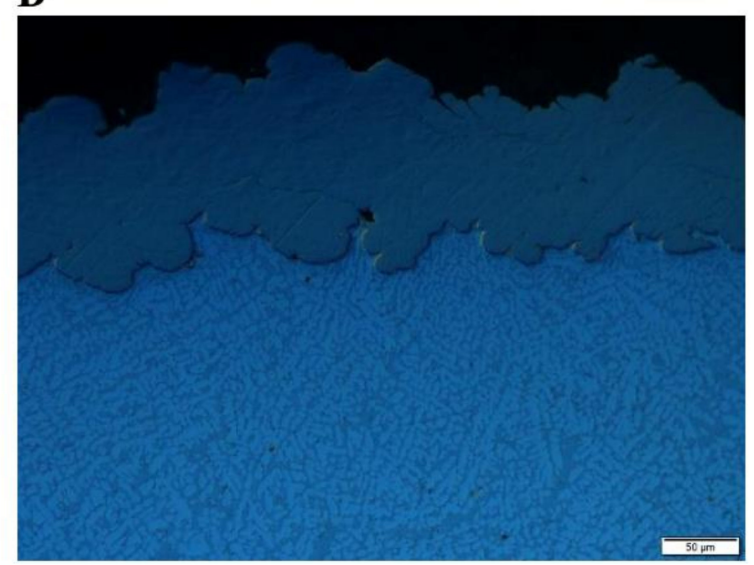

Figure 3. (A) Optical micrograph of the as-cast A365 HPDC. (B) Optical micrograph of the copper CGDS processed A365 HPDC sample. (C) Optical micrograph of the titanium CGDS processed A365 HPDC sample. (D) Optical micrograph of the nickel CGDS processed A365 HPDC sample. Black portions within the micrographs capture the mounting material. Various degrees of subsurface modification are observable within each micrograph provided. The scale bar embedded within each micrograph presented represents $50 \mu \mathrm{m}$. 
As for Figure 3B, a much less pronounced near-surface and subsurface microstructurally dendritic grain-scale texture was present within the copper-coated A365 substrate compared with the microstructure presented in Figure 3A. In contrast, the microstructural texture affiliated with the nickel coated A365 substrate, in Figure 3D, was more pronounced than that of the copper specimen in Figure $3 \mathrm{~B}$ and less gradually transitional than the microstructural texture found in Figure 3A. At the same time, it is also interesting to note that the copper samples resulted in the HPDC A365 substrate material, near the coated surface and coating-substrate interface, hydrodynamically flowing within the coating, and vice versa, via Kelvin-Helmholtz interfacial instabilities [30]. Nickel and titanium samples, however, did not achieve the same degree of interfacial intermixing between the substrate and deposited material.

The subsurface microstructure associated with the A365 material shown in Figure 3A, relative to the CGDS surface-modified A365 substrate materials shown in Figure 3B-D, raises interesting questions surrounding the degree of substrate material plastic deformation induced grain refinement and substrate erosion. From the micrograph of the substrate system, shown in Figure 3C, following CGDS processing with pure Ti feedstock, limited substrate erosion was observed. Said observation follows from the fact that the microstructural grain size gradient noted initially in Figure 3A remains and would have been retained if significant erosion had occurred since the as-cast microstructural texture's location followed within such a casting. As such, the Ti-based CGDS processing explored in the present work retained the fine grain size distribution towards the casting's surface and a coarser dendritic microstructure moving away from the Ti-A365 interface.

Based on Figure 3, the consolidated Ti CGDS coating's deposited particulates achieved insufficient particulate-particulate bonding with one another in the as-deposited state. In contrast, the nickel and copper deposits were relatively thinner. It is also evident that there are limited mechanical interlocking and interfacial mixing within the Ti-A365 system when compared with the other coating-substrate material combinations. Consequently, the Ti CGDS coatings' remarkable preservation of the as-cast subsurface microstructural features suggests that the mechanical properties, such as impact and fracture toughness, of the layered Ti-A365 system can be retained and enhanced when CGDS processing parameters are optimized. Furthermore, microstructural gradient preservation would likely be consistent with the work of Shivkumar et al. Both parties noted that finer grain sizes near cast aluminum surfaces would yield more desirable impact energies and fracture toughness's in proportion with the silicon phase spacing between grains [31].

There are two possible culprits related to the coarser grain size distribution in the subsurface region of the Cu-based CGDS-processed material relative to the Ni CGDS coated A365 system. One potential explanation surrounds the possibility that the $\mathrm{Cu}$ powders eroded the alloyed aluminum substrate to a much greater extent than that of the commercially pure Ni feedstock. The tendency for a material to be removed via erosive peening effects has become commonly understood by those in the field as more prominent when the particulate utilized maintains higher hardness than the substrate. Based on the work by Wei et al., which found that gas-atomized Ni powder had a hardness of 165.3 HVN [32], and the work of Sundberg et al., which reported a gas-atomized $\mathrm{Cu}$ powder hardness of $123 \mathrm{HVN}$ [33], it stands to reason that rapidly solidified particulate strength was not solely responsible for the observed difference in substrate erosion. Beyond the difference in particulate strength between the inertly atomized Ni powder and the air-atomized $\mathrm{Cu}$, the use of air-atomization for copper production can result in copper oxide film thickness of exceptional magnitude when compared with inertly atomized copper powder.

The second so-to-speak culprit follows from appreciable consideration of the $\mathrm{Cu}$ and $\mathrm{Ni}$ powders' surface oxidation state as far as CGDS processing implications are concerned. Nickel forms a passivating oxide-hydroxide layer(s) on the surface, as detailed by others [34-36]. In contrast, gas-atomized $\mathrm{Cu}$ has been found to form a non-passivating $\mathrm{Cu}_{2} \mathrm{O}$ surface film, as discussed by Sousa et al. in [37], which can range from at least 5 to $20 \mathrm{~nm}$ 
following inert gas-atomization and can continue to thicken over time [38]. Recent work by Razavinpar et al. found that gas-atomized, pure $\mathrm{Cu}$, particulate surface oxide film thicknesses doubled after only " 2 months of exposure to atmospheric conditions" [39]. Coupling such an understanding of copper surface film formation and thickness, in comparison with the passivated nature and much smaller thickness of Ni powder surface films, with work by Shikalov et al. surrounding supersonic microparticle deposition upon erodible substrate materials [40], unveils a potential framework for understanding how a softer material, i.e., $\mathrm{Cu}$, could have resulted in such pronounced erosion of the cast substrate relative to Ni.

Shikalov et al. discussed how substrate erosion during CGDS processing would continue to occur until a particular threshold is crossed concerning the number of particles impacting the substrate surface per unit area depending on deposition parameters. A combination of deficient impacting particles to break substrate oxides, the thick oxide shells, and not meeting critical velocities may explain copper's poor adhesion. It stands to reason that the long-term storage of the $\mathrm{Cu}$ feedstock before its use herein introduced a greater degree of substrate removal via erosion before mechanical and metallurgical bonding between the substrate and a portion of the particles that successfully surpassed the 1.3-times the critical impact velocity threshold of proposed by Tiamiyu et al. in [41].

The microstructures of the coated substrates after solution treating are shown in Figure 4. In each of the CGDS-processed HPDC Al 365 substrates, solution treatments resulted in the subsurface $\mathrm{Al} 365$ microstructure's thermal recrystallization. The dendritic texture initially present in the as-cast material, and partially present in the $\mathrm{Ni}$ and $\mathrm{Ti}$ samples, was no longer present in any subsurface(s) recorded in Figure 4. The recrystallized subsurface microstructures of the three coated specimens were unique to the feedstock metal and processing parameters utilized during CGDS. The mechanically induced subsurface microstructural modification that followed from CGDS processing was modified further via thermally induced chemical activity.
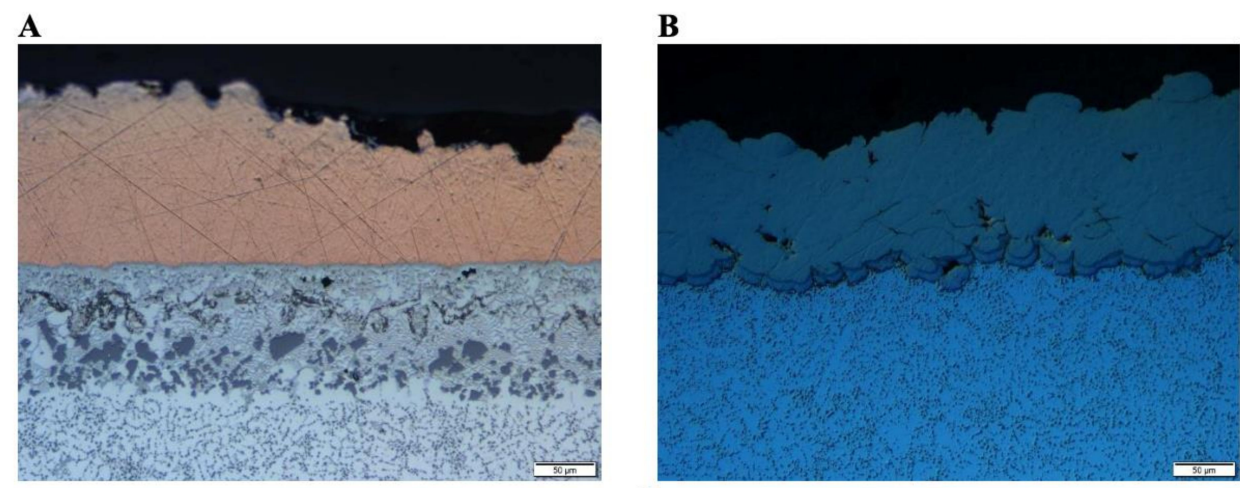

C

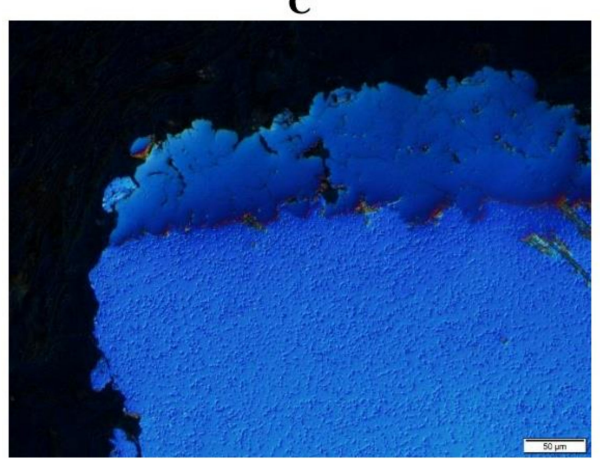

Figure 4. (A) Optical micrograph of the copper CGDS processed A365 HPDC system following solution heat-treating. (C) Optical micrograph of the titanium CGDS processed A365 HPDC system following solution heat-treating. (B) Optical micrograph of the nickel CGDS processed A365 HPDC system following solution heat-treating. Black portions within the micrographs capture the mounting material. The scale bars embedded within each micrograph presented represent $50 \mu \mathrm{m}$. 
The solution-treated $\mathrm{Cu}$ samples substrate's micrograph reveals a diverse intermetallicrich region that formed secondary phases and even precipitates in the substrate's diffusion zone followed by a relatively precipitate-free band of $\mathrm{Cu}$-enriched face-centered cubic (FCC) alpha-Al. Following the substrate diffusion zone, a conventional, solution treated, A3xx microstructure that houses standard secondary intermetallic phases between dendritic boundaries in the HPDC A365 can be seen; this microstructure can also be seen in the respective and comparable regions of relevance within Figure $4 B, C$.

Though the secondary phases within the HPDC A365 coated and thermally processed systems captured in Figure 4B,C are comparable with that of Figure 5A, the degree of diffusion of Ti and Ni into the HPDC A365 material following solution treating was much more reserved than that presented in Figure 4A for $\mathrm{Cu}$. Copper deposited samples after thermal processing showed more porosity near the interface, likely due to diffusion since no porosity was present immediately after consolidation. Conversely, the $\mathrm{Ni}$ and $\mathrm{Ti}$ deposits demonstrated more porosity in the coating(s) and little porosity in the substrate nearest the interface.

A

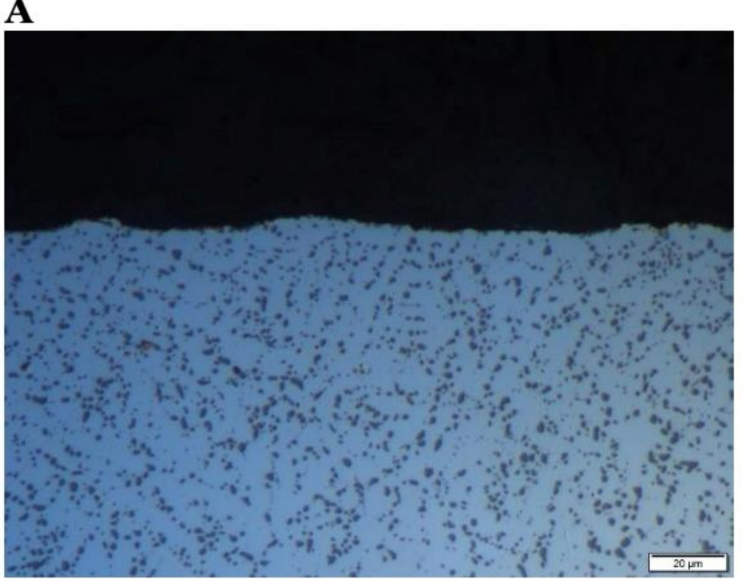

C

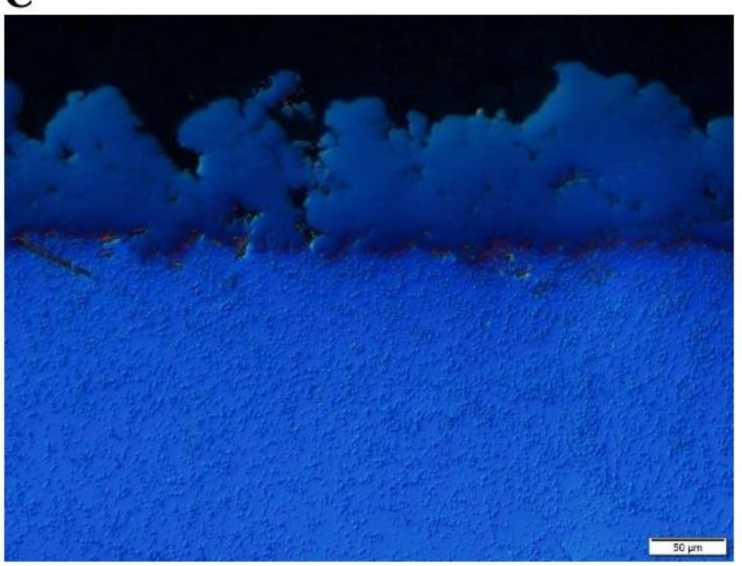

B

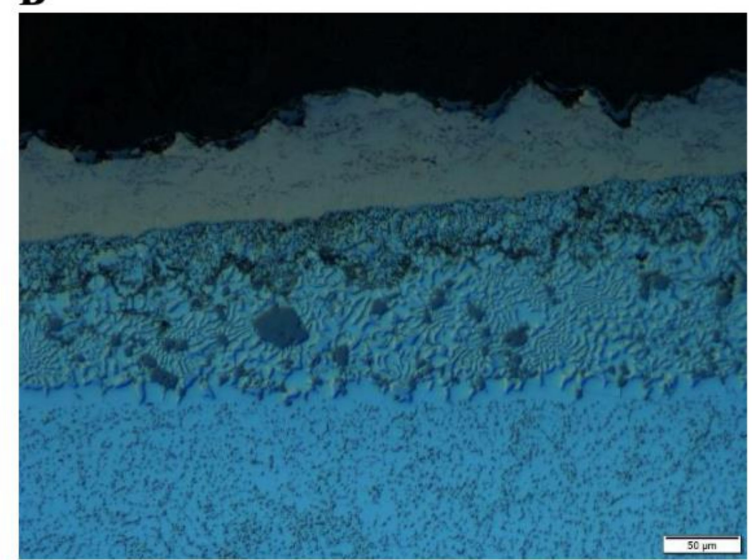

D

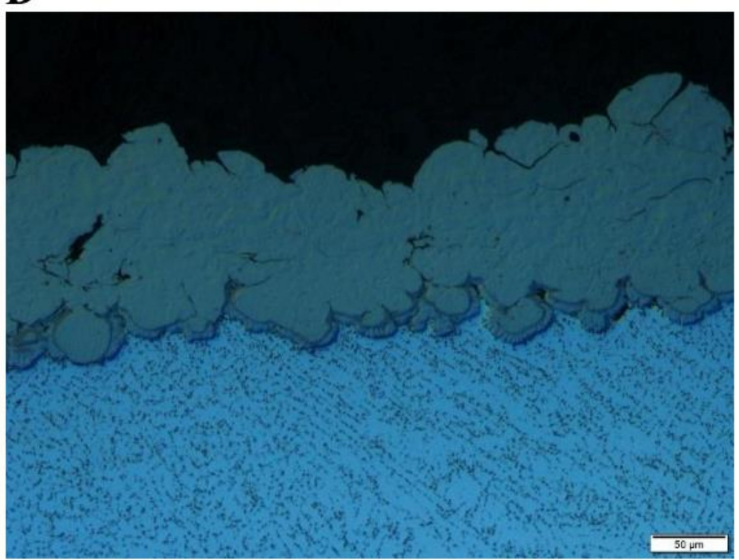

Figure 5. (a) Optical micrograph of the A365 HPDC system in the T6 condition. (B) Optical micrograph of the copper CGDS processed A365 HPDC system in the T6 condition. (C) Optical micrograph of the titanium CGDS processed A365 HPDC system in the T6 condition. (D) Optical micrograph of the nickel CGDS processed A365 HPDC system in the T6 condition. Black portions within the micrographs capture the mounting material. The scale bar embedded within each micrograph presented represents $50 \mu \mathrm{m}$.

The uncoated A365-T6 microstructure captured in Figure 5A was found to maintain a uniquely discernable microstructure compared with the as-cast A365 shown in Figure 3A. The morphology of the eutectic silicon-rich regions, which were found between the dendritic primary eutectic FCC Al matrix phases in the as-cast substrate material were shown to have undergone rounding, spheroidization, and ripening in a manner comparable with 
that observed by Ma et al. [42]. While Ma et al. also noted the persistent presence of Fe-rich intermetallics along grain boundaries following solution heat-treating, the $\mathrm{Mn}, \mathrm{Si}$, and $\mathrm{Mg}$ content of the HPDC A365 system under consideration herein promotes the formation of alpha-Fe $\left(\mathrm{Al}_{15}(\mathrm{Fe}, \mathrm{Mn})_{3} \mathrm{Si}_{2}\right)$ script-like precipitates in place of needle-like beta-Fe $\left(\mathrm{Al}_{5} \mathrm{FeSi}\right)$ phases [43]. The presence of alpha-Fe intermetallics in the as-cast and uncoated A365-T6 systems was consistent with the work of Liu et al., which also had alpha-Al grains, "fiber or short rod-like" eutectic Si-based phases, and alpha-Fe intermetallics [28].

One may note that the subsurface microstructural regions within the precipitationhardened HPDC A365 component no longer house the same degree of variability concerning the distance away from the surface that the as-cast A365 metal maintained. Such microscopy-based comparative evaluation of the subsurface microstructures of interest was also consistent with several studies, cited hereafter, that also identified coarser and more homogenous morphology throughout T6 postprocessed Al-Si-Mg-Mn castings $[28,44-46]$.

Copper cold spray coatings consolidated upon HPDC A365 underwent a T6 treatment cycle. The first layer is composed of the copper coating, the next distinct layer is the diffusion zone, and the final layer is the A365 substrate. EDS mapping shows the contents of each of these regions. The copper coating is dense with little to no porosity. The high impact of cold spray closed all gaps and provided an excellent coating method in this regard. Black streaks can be seen towards the top of the image, and these are bands of copper oxide.

A thin layer between the copper coating and the aluminum has developed, determined to be a continuous aluminum-copper phase, which is expected. According to EDS line scans in Figure 6, all secondary phases of aluminum-copper are $\mathrm{Al}_{2} \mathrm{Cu}$. This was confirmed via EDS point scans. Since the solution treatment hold-time was only $80 \mathrm{~min}$ at $500{ }^{\circ} \mathrm{C}$, other intermetallic compounds formed other than those presented in Funamizu's work [25], which were not found in under such conditions. If a significantly longer solution treatment time was allowed, four other phases might have appeared based on the equilibrium phase diagram and even Funamizu's findings. $\mathrm{Cu}$ is expected to have gone into solidsolution within the $\mathrm{Al}$ matrix in locations where a secondary Al-Cu phase did not form. Copper oxide formation was expected due to the high temperature and air exposure in the solution treatment step of the T6 process. In the copper diffusion zone seen in Figure 7 , many features have formed.

The finger-like phases in the bulk of the diffusion zone are also $\mathrm{Al}_{2} \mathrm{Cu}$ but formed in a discontinuous manner. Another feature of note is the large silicon phases that form in the diffusion zone. The silicon agglomerated together in the region where significant copper diffusion occurred. Driving forces for this agglomeration could arise from copper being held in the aluminum matrix and kicking silicon out of the solution. It is predicted that for silicon to reduce its energy while in the aluminum matrix, silicon agglomerated into large polygons. Copper, when not in an intermetallic phase, was found to be about $5 \mathrm{wt}$. \% in solid solution to a depth of $100 \mu \mathrm{m}$ below the copper-aluminum interface and silicon was not generally found in solution in those same regions. Black "holes" that appear to look like porosity in the diffusion zone were found to be magnesium oxide. EDS mapping found in Figure 7 shows that on the black holes, magnesium and oxygen signals are strongly detected. Approaching the bottom of the diffusion zone, when copper was no longer seen, phases of $\mathrm{Al}_{2} \mathrm{Cu}$ no longer appear, and finer silicon precipitates expected in the bulk material are well dispersed. 


\title{
EDS Line Scan: Cu CS on A365 T6
}

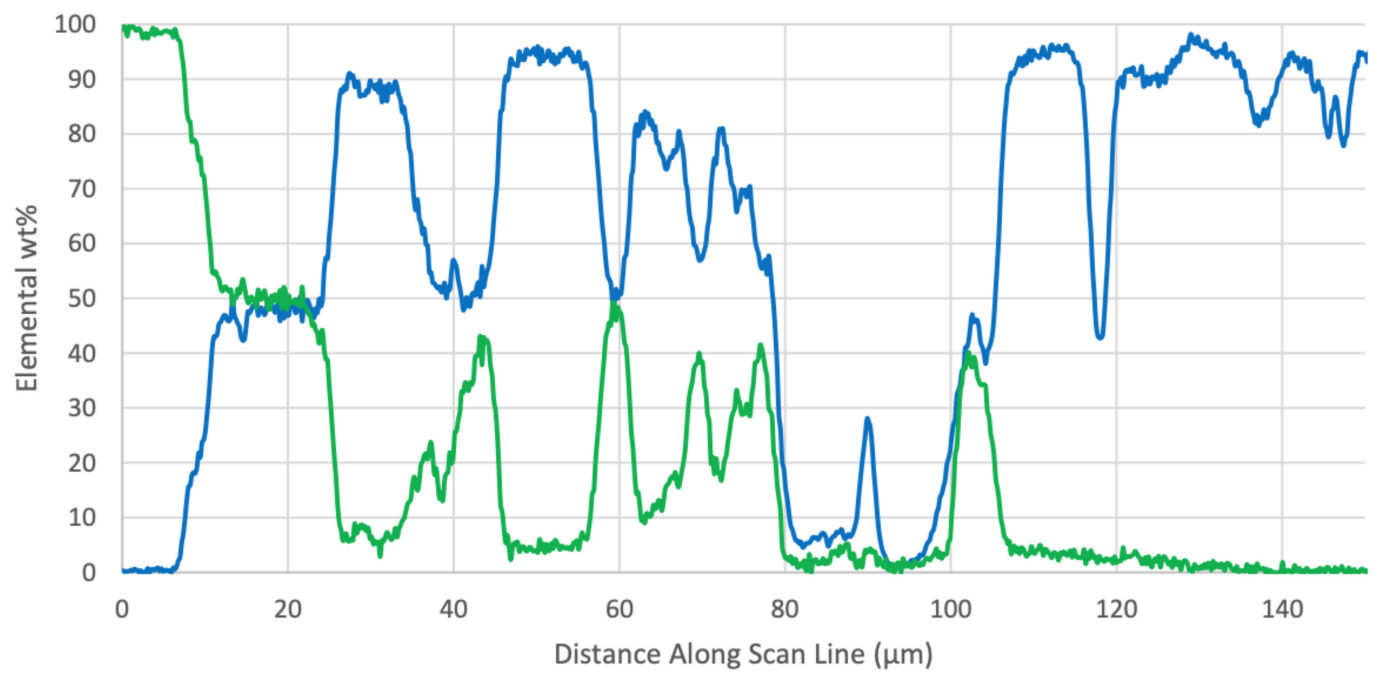

$-\mathrm{Al} \mathrm{Wt} \% \quad \mathrm{Cu}$ Wt\%

Figure 6. Presentation of the EDS line scan recorded for the Cu CGDS coated HPDC A365 substrate system in the thermally postprocessed condition.

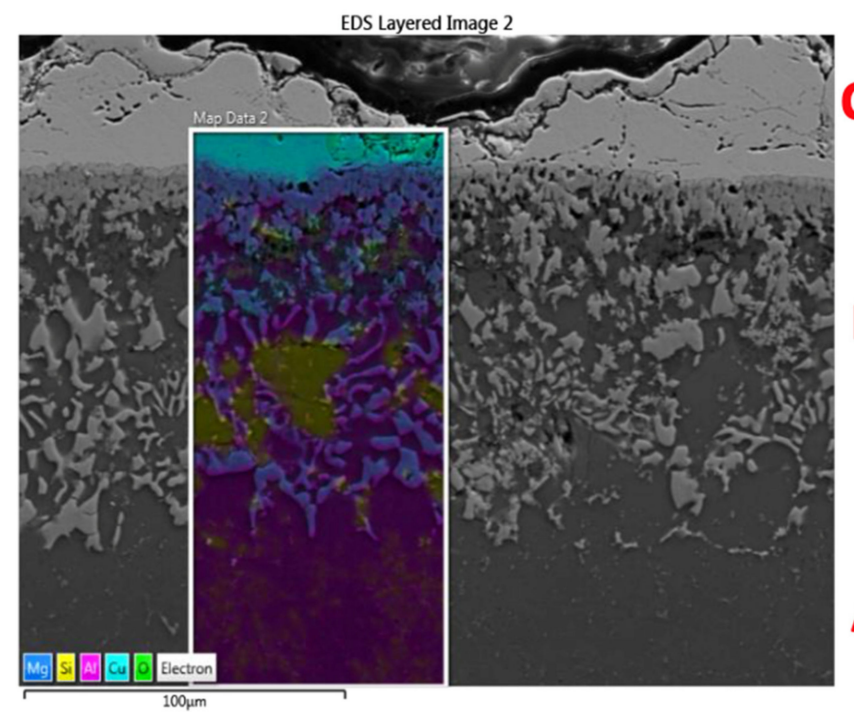

Copper Coating

\author{
Diffusion Zone
}

A365 Substrate
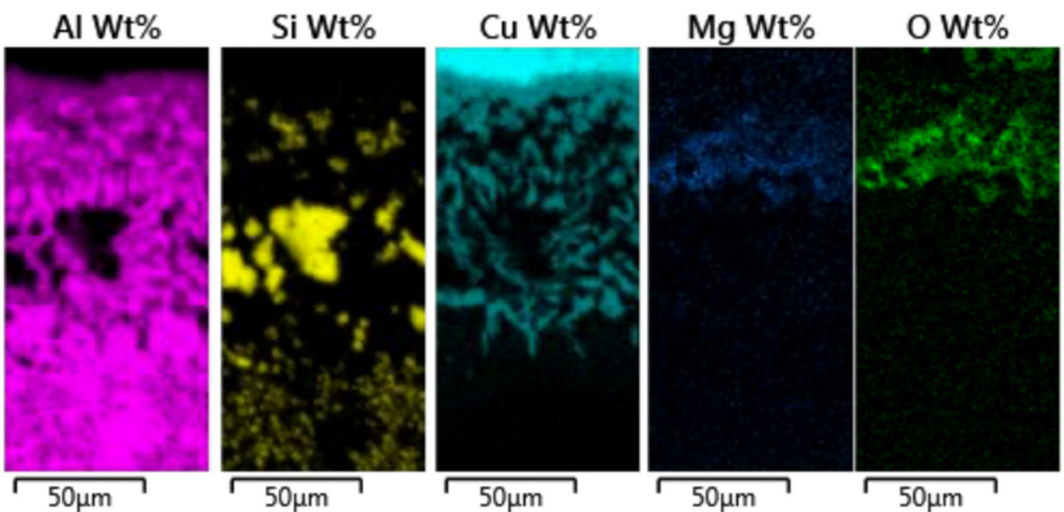

Figure 7. Presentation of the EDS mapping recorded for the Cu CGDS coated HPDC A365 substrate system in the thermally postprocessed condition. 
Nickel samples differed from both copper and titanium results in that very little, if any, nickel was held in solid solution. Intermetallics of nickel and aluminum formed, but EDS was not the appropriate method for differentiating the potential phases formed due to each layer's small thickness and compositional similarity. According to the EDS line scans conducted, potential phases to have formed include $\mathrm{Ni}_{2} \mathrm{Al}_{3}, \mathrm{NiAl}_{3}$, and $\mathrm{NiAl}$, as exemplified by Figure 8. If longer solution treatment times were available, all intermetallics expected should form. A feature of note for the nickel diffusion zone was how continuous and relatively smooth the intermetallic layer was compared to copper's intermetallic layer. Nickel does not appear to have been held in a solid solution with the aluminum matrix. Nevertheless, EDS mapping was also applied, as shown in Figure 9.

\section{EDS Line Scan: Ni CS on A365 T6}

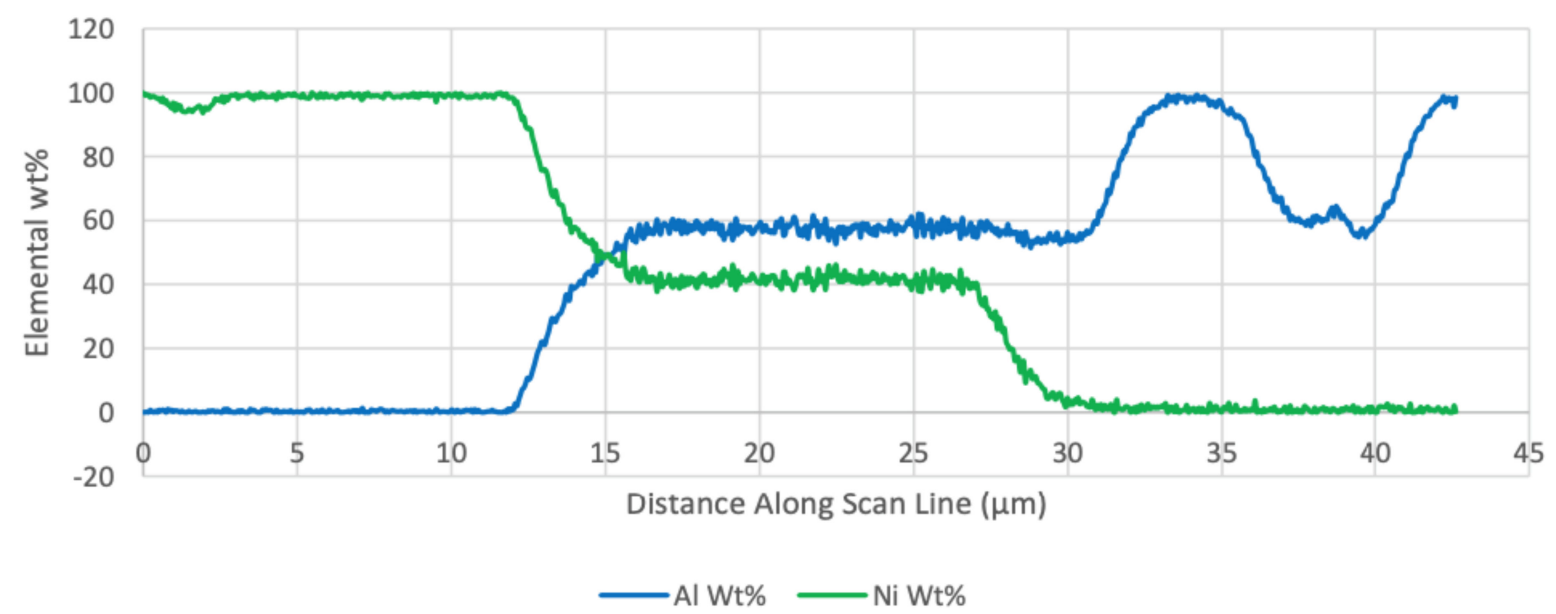

Figure 8. Presentation of the EDS line scan recorded for the Ni CGDS coated HPDC A365 substrate system in the thermally postprocessed condition.

Titanium results from EDS show no significant diffusion into the surface of the aluminum substrate. Figure 10 shows the line scans of aluminum and titanium against distance along with the scan. In this figure, the titanium coating began on the right-hand side and moved leftwards. An insignificant amount of titanium can be found in the aluminum substrate due to the electron beam's probe size in EDS analysis. Dips in aluminum content along the scan are due to formations of silicon phases in the bulk of the sample.

A select set of CGDS-based publications were cited in Section 1 as a means of highlighting how prior work has considered the use of CGDS surface modification for improved mechanical performance and microstructural properties. The subset of works cited at the beginning of the present article does not encapsulate a complete collection of the previously published work of relevance to date. The present section of the current manuscript will briefly build upon how links between reported results and the results presented in this body of work can serve as a pathway for contextualizing the findings.

Liang et al. demonstrated the ability to deposit Zn-Al CGDS coatings onto an interstitial-free $\mathrm{Ti}-\mathrm{Nb}$ steel substrate system [47]. Liang et al. studied interfacial compound formation between the $\mathrm{Zn}$ - $\mathrm{Al}$ coating and substrate when diffusion-driven annealing heat treatments were applied as a postprocessing step at $400^{\circ} \mathrm{C}$. The researchers documented $\mathrm{Fe}-\mathrm{Zn}$ and Fe-Al-Zn interfacial compounds' construction upon applying the annealing treatment for $60 \mathrm{~min}$. At the closing of their work, the researchers identified and detailed how enhanced erosion resistance of the automotive steel substrate and enhanced corrosion resistance followed from a hold time of $60 \mathrm{~min}$ during annealing [47]. The current work presents similar findings of foreign phases formed not inherent to the substrate via EDS and micrographs. 


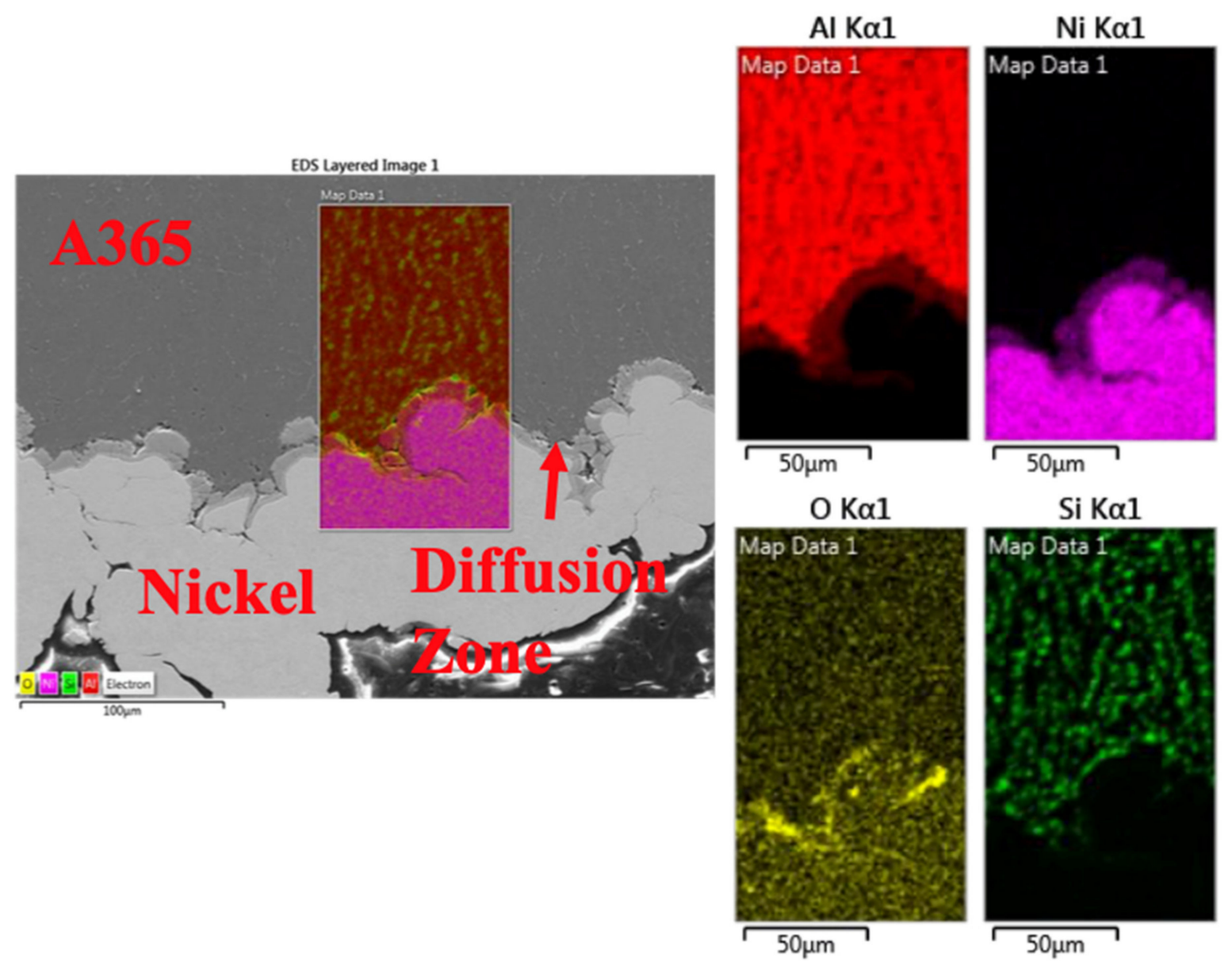

Figure 9. Presentation of the EDS mapping recorded for the Ni CGDS coated HPDC A365 substrate system in the thermally postprocessed condition.

\section{EDS Line Scan: Ti CS on A365 T6}

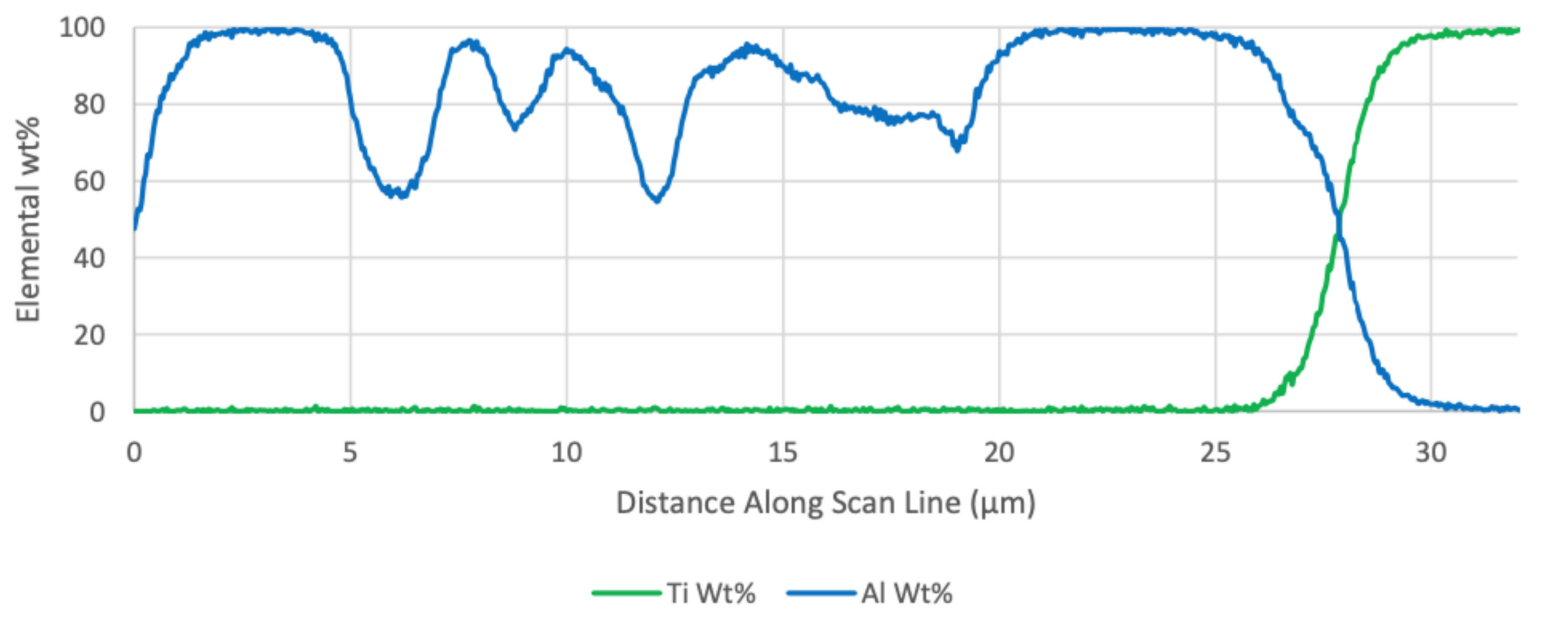

Figure 10. Presentation of the EDS line scan recorded for the Ti CGDS coated HPDC A365 substrate system in the thermally postprocessed condition.

From the discussion and contextualization procured by way of referencing [47] and [48] above, one may readily appreciate the fact that those mentioned above were formulated as a means of highlighting how prior work has considered the use of CGDS sur- 
face modification for application-specific performance-driven scenarios. While additional discussion could have been presented next surrounding the remaining aforementioned topical clusters within the academic literature of relevance presented to date, the current scope, aims, and objectives motivated the authors of the present article to reference the remaining articles not considered herein for curious readers [49-63].

\section{Conclusions}

In this work, we have substantiated the identification of Ti and Ni CGDS deposition as a promising surface modification technique for cost-effective near-surface property enhancement of A365 aluminum alloy HPDC materials. Cu CGDS, the third CGDS deposition feedstock considered during this work, was eliminated as a prospective coating material for the present purposes since thermally mediated Cu CGDS atomic diffusion into the HPDC A365 subsurface region resulted in deleterious microstructural and property evolution. Necessary contextualization of the present observations and findings recorded herein has been provided, thus also addressing the standing need for a resource that captures most of the literature on intermetallic CGDS processing published to date.

Streamlined manufacturing potential was explored herein too, which identified Ti CGDS surface modification as a viably integrative step where CGDS processing induced subsurface property enhancement could be applied immediately following solidification and then followed by standard T6 thermal treatment. In contrast, a second suitable CGDS processing approach using $\mathrm{Ni}$ feedstock was found to be less successful. Limited success partly followed from the observation that the thermal postprocessing of the Ni CGDS coated HPDC A365 specimens formed Ni-Al intermetallics. Additional sources of said limited success include diffusion zone formation near the coating-substrate interface, which promoted a greater degree of polygonization, i.e., dislocation rearrangement such that ordered subgrains formed during elevated-temperature recrystallization within the subsurface region. Furthermore, the impact-induced substrate surface erosion and the partial removal of the texture of the as-cast A365 occurred when Ni was deposited via CGDS, suggesting that the A365 material in the T6 condition would be sufficiently strengthened relative to the as-cast condition such that impact-induced erosion may be avoided. In any case, when through-processing stages were treated, and Ti was utilized as the feedstock, no secondary Ti-Al intermetallic compounds were found to have nucleated, as evidenced by EDS analysis. Simultaneously, atomic Ti enriched the A365 solid solution in the subsurface region of the thermally postprocessed bimetallic system.

Unlike $\mathrm{Cu}$ particulate feedstock, which was ruled out so far as future works are concerned, Ni particulate feedstocks may still be pursued; however, the A365-T6 condition should be procured before Ni CGDS surface modification and potential postprocessing of the coating-substrate combination after that. In keeping with the consideration of future work, much more research and development remain to be completed. Such future work includes, but is not limited to, the following: tensile and fatigue testing of properly prepared mechanical testing specimens, thermal processing optimization and CGDS processing parameter optimization, and deposition of spherical Ti powder rather than sponge granules for ever more significant property enhancement.

Author Contributions: Conceptualization, B.C.S., A.T., B.M., and D.L.C.; methodology, B.C.S., A.T., B.M., and D.L.C.; validation, B.C.S. and A.T.; formal analysis, B.C.S. and A.T.; investigation, B.C.S. and A.T.; resources, B.C.S., A.T., B.M., and D.L.C.; data curation, B.C.S., A.T., B.M., and D.L.C.; writing-original draft preparation, B.C.S. and A.T.; writing — review and editing, B.C.S., A.T., B.M., and D.L.C.; visualization, A.T.; supervision, B.M. and D.L.C.; project administration, B.M. and D.L.C.; funding acquisition, B.M. and D.L.C. All authors have read and agreed to the published version of the manuscript. 
Funding: This research was funded by the Advanced Casting Research Center, which was housed as one of four research centers of the Metal Processing Institute, an industry-university alliance that is housed at Worcester Polytechnic Institute (Worcester, MA, USA), at the time the presented research activities were performed. At the time, the funded project title was "Improvement of Impact Strength and Fracture Toughness of Castings through Chemically Induced Residual Stresses".

Institutional Review Board Statement: Not applicable.

Informed Consent Statement: Not applicable.

Data Availability Statement: The data presented in this study will be made available upon request from the corresponding author.

Acknowledgments: The authors wish to thank the then following Metal Processing Institute's Advanced Casting Research Center Focus Group Members: Focus Group Chair David Weiss, Vice President of Research and Development at Eck Industries, Inc. (Manitowoc, WI, USA); Hal Gerber, Director Business Development and Strategy at Albany Chicago Co./Shiloh Industries, Inc. (Valley City, OH, USA); Denis Massinon, then North America Technical Director of Montupet (Clichy, Ile-de-France, France) and now Metallurgy and Material Engineering Consultant at D3ME Consulting (Gargas, France); Lin Zhang of Fiat Chrysler Automobiles; Stephen (Steve) P. Udvardy, President of the North American Die Casting Association (Arlington Heights, IL, USA); Christof Heisser, then President of MAGMA Foundry Technologies, Inc. (Schaumburg, IL, USA) and now Vice President of Sales and Marketing at Performance Friction (Colver, SC, USA); and Kevin R. Anderson, Senior Technical Fellow for Brunswick Corporation in the Mercury Marine Division (Fond Du Lac, Wisconsin, USA). A.T. also wishes to acknowledge Diran Apelian, then Howmet Professor of Engineering at Worcester Polytechnic Institute (Worcester, MA, USA) and now Distinguished Professor of Materials Science and Engineering in The Henry Samueli School of Engineering at the University of California, Irvine (Irvine, CA, USA) for his mentorship. A.T. also wishes to thank Richard D. Sisson, Jr., Technical Director Head of the Center for Heat Treating Excellence, which is based out of Worcester Polytechnic Institute, and George F. Fuller Professor of Mechanical Engineering too, for his advisement. Finally, we wish to thank John K. Potter, Timothy J. Eden, and Jeremy M. Schreiber, of the Applied Research Laboratory at The Pennsylvania State University (State College, PA, USA) for their support and time surrounding the procurement of cold-sprayed samples.

Conflicts of Interest: The authors declare no conflict of interest. The funders had no role in the collection, analyses, or interpretation of data; in the writing of the manuscript; or in the decision to publish the results. However, the funders, i.e., Metals Processing Institute's Advanced Casting Research Center Focus Group Members, contributed to identifying the current industrial metals processing need for cost-effective aluminum alloy casting property modifications towards premium alloy characteristics.

\section{References}

1. Alkhimov, A.; Papyrin, A.; Kosarev, V. Gas-Dynamic Spraying Method for Applying a Coating. US Patent 5302414,12 April 1994.

2. Stoltenhoff, T.; Kreye, H.; Richter, H.J. An Analysis of the Cold Spray Process and Its Coatings. J. Therm. Spray Technol. 2002, 11, 542-550. [CrossRef]

3. Petráčková, K.; Kondás, J.; Guagliano, M. Fixing a hole (with cold spray). Int. J. Fatigue 2018, 110, 144-152. [CrossRef]

4. Sova, A.; Grigoriev, S.; Okunkova, A.; Smurov, I. Potential of cold gas dynamic spray as additive manufacturing technology. Int. J. Adv. Manuf. Technol. 2013, 69, 2269-2278. [CrossRef]

5. Wang, X.; Feng, F.; Klecka, M.A.; Mordasky, M.D.; Garofano, J.K.; El-Wardany, T.; Nardi, A.; Champagne, V.K. Characterization and modeling of the bonding process in cold spray additive manufacturing. Addit. Manuf. 2015, 8, 149-162. [CrossRef]

6. Yin, S.; Suo, X.; Liao, H.; Guo, Z.; Wang, X. Significant influence of carrier gas temperature during the cold spray process. Surf. Eng. 2014, 30, 443-450. [CrossRef]

7. Sinclair-Adamson, R.; Luzin, V.; Duguid, A.; Kannoorpatti, K.; Murray, R. Residual Stress Distributions in Cold-Sprayed Copper 3D-Printed Parts. J. Therm. Spray Technol. 2020, 29, 1525-1537. [CrossRef]

8. Irissou, E.; Legoux, J.-G.; Ryabinin, A.N.; Jodoin, B.; Moreau, C. Review on Cold Spray Process and Technology: Part I-Intellectual Property. J. Therm. Spray Technol. 2008, 17, 495-516. [CrossRef]

9. Singh, H.; Sidhu, T.S.; Kalsi, S.B.S.; Karthikeyan, J. Development of cold spray from innovation to emerging future coating technology. J. Brazilian Soc. Mech. Sci. Eng. 2013, 35, 231-245. [CrossRef]

10. Saboori, A.; Biamino, S.; Valente, A.; Gitardi, D.; Basile, G.; Lombardi, M.; Fino, P. The capacity of cold spray additive manufacturing technology for metallic part repairing. In Proceedings of the Europe PM 2018 Congress and Exhibition, Bilbao, Spain, 14-18 October 2018. 
11. Cavaliere, P.; Silvello, A. Processing conditions affecting residual stresses and fatigue properties of cold spray deposits. Int. J. Adv. Manuf. Technol. 2015, 81, 1857-1862. [CrossRef]

12. Belsito, D. Application of Computational Thermodynamic and Solidification Kinetics to Cold Sprayable Powder Alloy Design. Ph.D. Thesis, Worcester Polytechnic Institute, Worcester, MA, USA, 2014.

13. Yeom, H.; Sridharan, K. Cold spray technology in nuclear energy applications: A review of recent advances. Ann. Nucl. Energy 2021, 150, 107835. [CrossRef]

14. Rokni, M.R.; Widener, C.A.; Champagne, V.K.; Crawford, G.A. Microstructure and mechanical properties of cold sprayed 7075 deposition during non-isothermal annealing. Surf. Coatings Technol. 2015, 276, 305-315. [CrossRef]

15. Rokni, M.R.; Widener, C.A.; Ozdemir, O.C.; Crawford, G.A. Microstructure and mechanical properties of cold sprayed $6061 \mathrm{Al}$ in As-sprayed and heat treated condition. Surf. Coatings Technol. 2017, 309, 641-650. [CrossRef]

16. Jafarlou, D.M.; Walde, C.; Champagne, V.K.; Krishnamurty, S.; Grosse, I.R. Influence of cold sprayed Cr3C2-Ni coating on fracture characteristics of additively manufactured 15Cr-5Ni stainless steel. Mater. Des. 2018, 155, 134-147. [CrossRef]

17. Yang, J.; Yang, J.; Xie, J.; Wang, Q.; Qu, K. Improved fatigue crack propagation performance of Q355B steel with cold-sprayed A5052 and Al coatings. Surf. Coatings Technol. 2019, 378, 125000. [CrossRef]

18. Wolfe, D.; Eden, T. Cold spray particle deposition for improved wear resistance. In The Cold Spray Materials Deposition Process; Elsevier: Amsterdam, The Netherlands, 2007; pp. 264-301.

19. Chromik, R.R.; Alidokht, S.A.; Shockley, J.M.; Zhang, Y. Tribological Coatings Prepared by Cold Spray. In Cold-Spray Coatings; Springer International Publishing: Cham, Switzerland, 2018; pp. 321-348.

20. Murray, J.W.; Zuccoli, M.V.; Hussain, T. Heat Treatment of Cold-Sprayed C355 Al for Repair: Microstructure and Mechanical Properties. J. Therm. Spray Technol. 2018, 27, 159-168. [CrossRef]

21. Champagne, V.K.; Gabriel, B.; Villafuerte, J. Cold spray coatings to improve the corrosion resistance of magnesium (Mg) alloys In Corrosion Prevention of Magnesium Alloys; Elsevier: Amsterdam, The Netherlands, 2013; pp. $414-445$.

22. Huang, C.J.; Yan, X.C.; Li, W.Y.; Wang, W.B.; Verdy, C.; Planche, M.P.; Liao, H.L.; Montavon, G. Post-spray modification of cold-sprayed Ni-Ti coatings by high-temperature vacuum annealing and friction stir processing. Appl. Surf. Sci. 2018, 451, 56-66. [CrossRef]

23. Li, J.; Zhang, Y.; Cao, X.; Zeng, Q.; Zhuang, Y.; Qian, X.; Chen, H. Accelerated discovery of high-strength aluminum alloys by machine learning. Commun. Mater. 2020, 1, 73. [CrossRef]

24. Jozwik, P.; Polkowski, W.; Bojar, Z. Applications of Ni3Al Based Intermetallic Alloys-Current Stage and Potential Perceptivities. Materials 2015, 8, 2537-2568. [CrossRef]

25. Deevi, S.C.; Sikka, V.K. Nickel and iron aluminides: An overview on properties, processing, and applications. Intermetallics 1996, 4, 357-375. [CrossRef]

26. Chen, Z.; Yan, K. Grain refinement of commercially pure aluminum with addition of Ti and Zr elements based on crystallography orientation. Sci. Rep. 2020, 10, 16591. [CrossRef]

27. Arzamasov, B.N.; Babich, S.G.; Kirichenko, L.G.; Knyazheva, V.M.; Silaeva, V.I.; Solov'eva, T.V. Properties of aluminum alloys with a titanium nitride coating. Met. Sci. Heat Treat. 1994, 36, 308-312. [CrossRef]

28. Liu, F.; Zhao, H.; Yang, R.; Sun, F. Microstructure and Mechanical Properties of High Vacuum Die-Cast AlSiMgMn Alloys at as-Cast and T6-Treated Conditions. Materials 2019, 12, 2065. [CrossRef]

29. Padmanaban, S.; Subramanian, R.; Anburaj, J.; Thillairajan, K. Rheo-Die-Casting of Al-Si-Mg Alloy and Al-Si-Mg/ SiCp Composites: Microstructure and Wear Behavior. Mater. Res. 2020, 23. [CrossRef]

30. Viscusi, A.; Astarita, A.; Gatta, R.D.; Rubino, F. A perspective review on the bonding mechanisms in cold gas dynamic spray. Surf. Eng. 2019, 35, 743-771. [CrossRef]

31. Shivkumar, S.; Wang, L.; Keller, C. Impact properties of A356-T6 alloys. J. Mater. Eng. Perform. 1994, 3, 83-90. [CrossRef]

32. Wei, Y.-K.; Li, Y.-J.; Zhang, Y.; Luo, X.-T.; Li, C.-J. Corrosion resistant nickel coating with strong adhesion on AZ31B magnesium alloy prepared by an in-situ shot-peening-assisted cold spray. Corros. Sci. 2018, 138, 105-115. [CrossRef]

33. Sundberg, K.; Sousa, B.C.; Schreiber, J.; Walde, C.E.; Eden, T.J.; Sisson, R.D.; Cote, D.L. Finite Element Modeling of Single-Particle Impacts for the Optimization of Antimicrobial Copper Cold Spray Coatings. J. Therm. Spray Technol. 2020, 29, 1847-1862. [CrossRef]

34. Uchikoshi, T.; Sakka, Y.; Yoshitake, M.; Yoshihara, K. A study of the passivating oxide layer on fine nickel particles. Nanostruct. Mater. 1994, 4, 199-206. [CrossRef]

35. Mrowec, S.; Grzesik, Z. Oxidation of nickel and transport properties of nickel oxide. J. Phys. Chem. Solids 2004, 65, 1651-1657. [CrossRef]

36. Song, P.; Wen, D.; Guo, Z.X.; Korakianitis, T. Oxidation investigation of nickel nanoparticles. Phys. Chem. Chem. Phys. 2008, 10, 5057. [CrossRef]

37. Sousa, B.C.; Sundberg, K.L.; Gleason, M.A.; Cote, D.L. Understanding the Antipathogenic Performance of Nanostructured and Conventional Copper Cold Spray Material Consolidations and Coated Surfaces. Crystals 2020, 10, 504. [CrossRef]

38. Sousa, B.C.; Gleason, M.A.; Haddad, B.; Champagne, V.K.; Nardi, A.T.; Cote, D.L. Nanomechanical Characterization for Cold Spray: From Feedstock to Consolidated Material Properties. Metals 2020, 10, 1195. [CrossRef]

39. Razavipour, M.; Rahmati, S.; Zúñiga, A.; Criado, D.; Jodoin, B. Bonding Mechanisms in Cold Spray: Influence of Surface Oxidation During Powder Storage. J. Therm. Spray Technol. 2020. [CrossRef] 
40. Shikalov, V.S.; Klinkov, S.V.; Kosarev, V.F. Cold spray deposition of aluminum coating onto an erodible material. Thermophys. Aeromech. 2019, 26, 729-737. [CrossRef]

41. Tiamiyu, A.A.; Sun, Y.; Nelson, K.A.; Schuh, C.A. Site-specific study of jetting, bonding, and local deformation during highvelocity metallic microparticle impact. Acta Mater. 2021, 202, 159-169. [CrossRef]

42. Ma, S.; Maniruzzaman, M.D.; MacKenzie, D.S.; Sisson, R.D. A Methodology to Predict the Effects of Quench Rates on Mechanical Properties of Cast Aluminum Alloys. Metall. Mater. Trans. B 2007, 38, 583-589. [CrossRef]

43. 365.0 (Silafont ${ }^{\circledR}-36$ ) and A365.0 (Aural®-2/-3)[1]: Low-Iron Premium Die-Casting Alloys. In Properties and Selection of Aluminum Alloys; Anderson, K. (Ed.) A.S.M. International: New York, NY, USA, 2019; pp. 561-563.

44. Cai, Q.; Mendis, C.L.; Chang, I.T.H.; Fan, Z. Effect of short T6 heat treatment on the microstructure and the mechanical properties of newly developed die-cast Al-Si-Mg-Mn alloys. Mater. Sci. Eng. A 2020, 788, 139610. [CrossRef]

45. Ding, J.; Miao, S.; Ma, B.; Xia, X.; Qiu, C.; Chen, X. Effect of Solution Treatment on Microstructure and Mechanical Properties of A356.2 Aluminum Alloy Treated With Al-Sr-La Master Alloy. Adv. Eng. Mater. 2018, 20, 1701173. [CrossRef]

46. Yuan, Z.; Guo, Z.; Xiong, S. Microstructure evolution of modified die-cast AlSi10MnMg alloy during solution treatment and its effect on mechanical properties. Trans. Nonferrous Met. Soc. China 2019, 29, 919-930. [CrossRef]

47. Liang, Y.L.; Wang, Z.B.; Zhang, J.B.; Lu, K. Formation of interfacial compounds and the effects on stripping behaviors of a cold-sprayed Zn-Al coating on interstitial-free steel. Appl. Surf. Sci. 2015, 340, 89-95. [CrossRef]

48. Nikbakht, R.; Assadi, H.; Jodoin, B. Intermetallic Phase Evolution of Cold-Sprayed Ni-Ti Composite Coatings: Influence of As-Sprayed Chemical Composition. J. Therm. Spray Technol. 2020. [CrossRef]

49. Wang, Q.; Birbilis, N.; Zhang, M.-X. On the Formation of a Diffusion Bond from Cold-Spray Coatings. Metall. Mater. Trans. A 2012, 43, 1395-1399. [CrossRef]

50. Spencer, K.; Zhang, M.-X. Heat treatment of cold spray coatings to form protective intermetallic layers. Scr. Mater. 2009, 61, 44-47. [CrossRef]

51. Yin, S.; Xie, Y.; Suo, X.; Liao, H.; Wang, X. Interfacial bonding features of Ni coating on Al substrate with different surface pretreatments in cold spray. Mater. Lett. 2015, 138, 143-147. [CrossRef]

52. Huang, R.; Ma, W.; Fukanuma, H. Development of ultra-strong adhesive strength coatings using cold spray. Surf. Coatings Technol. 2014, 258, 832-841. [CrossRef]

53. Bu, H.; Yandouzi, M.; Lu, C.; Jodoin, B. Effect of heat treatment on the intermetallic layer of cold sprayed aluminum coatings on magnesium alloy. Surf. Coatings Technol. 2011, 205, 4665-4671. [CrossRef]

54. Ning, X.-J.; Kim, J.-H.; Kim, H.-J.; Lee, C. Characteristics and heat treatment of cold-sprayed Al-Sn binary alloy coatings. Appl. Surf. Sci. 2009, 255, 3933-3939. [CrossRef]

55. Wang, J.; Kong, L.; Li, T.; Xiong, T. High temperature oxidation behavior of Ti(Al,Si) 3 diffusion coating on $\gamma$-TiAl by cold spray. Trans. Nonferrous Met. Soc. China 2016, 26, 1155-1162. [CrossRef]

56. Lee, H.; Shin, H.; Ko, K. Effects of Gas Pressure of Cold Spray on the Formation of Al-Based Intermetallic Compound. J. Therm. Spray Technol. 2010, 19, 102-109. [CrossRef]

57. Wang, J.; Kong, L.; Li, T.; Xiong, T. Oxidation Behavior of Thermal Barrier Coatings with a TiAl3 Bond Coat on $\gamma$-TiAl Alloy. J. Therm. Spray Technol. 2015, 24, 467-475. [CrossRef]

58. Novoselova, T.; Celotto, S.; Morgan, R.; Fox, P.; O’Neill, W. Formation of TiAl intermetallics by heat treatment of cold-sprayed precursor deposits. J. Alloys Compd. 2007, 436, 69-77. [CrossRef]

59. Anupam, A.; Kumar, S.; Chavan, N.M.; Murty, B.S.; Kottada, R.S. First report on cold-sprayed AlCoCrFeNi high-entropy alloy and its isothermal oxidation. J. Mater. Res. 2019, 34, 796-806. [CrossRef]

60. Li, W.-Y.; Li, C.-J.; Liao, H.; Coddet, C. Effect of heat treatment on the microstructure and microhardness of cold-sprayed tin bronze coating. Appl. Surf. Sci. 2007, 253, 5967-5971. [CrossRef]

61. Dean, S.W.; Potter, J.K.; Yetter, R.A.; Eden, T.J.; Champagne, V.; Trexler, M. Energetic intermetallic materials formed by cold spray. Intermetallics 2013, 43, 121-130. [CrossRef]

62. Leshchinsky, E.; Sobiesiak, A.; Maev, R. Intermetallic Al-, Fe-, Co- and Ni-Based Thermal Barrier Coatings Prepared by Cold Spray for Applications on Low Heat Rejection Diesel Engines. J. Therm. Spray Technol. 2018, 27, 456-470. [CrossRef]

63. Won, J.; Kim, J.; Lee, S.; Lee, C.; Lee, S.; Kim, S.J. Effect of intermetallic compounds on the bonding state of kinetic sprayed Al deposit on $\mathrm{Cu}$ after heat-treatment. Surf. Coatings Technol. 2016, 302, 39-46. [CrossRef] 